\title{
ERRATUM
}

Yuichi Miura $\cdot$ Sek Mardy $\cdot$ Yutaka Awaya Kenji Nihei · Fumio Endo · Ichiro Matsuda Yasuhiro Indo

\section{Mutation and polymorphism analysis of the TRKA (NTRK1) gene encoding a high-affinity receptor for nerve growth factor in congenital insensitivity to pain with anhidrosis (CIPA) families}

Published online: 3 May 2000

(C) Springer-Verlag 2000

Hum Genet (2000) 106:116-124

Inadvertently, four errors appeared in Fig. 1 and its legend. In the upper box of Fig. 1i, "D648C" and "EcoRV" should be "R648C" and "NspI", respectively. In the corresponding part of the figure legend, "Asp $\rightarrow$ Cys" should be "Arg $\rightarrow$ Cys". In the upper box of Fig. $1 \mathrm{j}$, "NspI" should be "EcoRV".

The online version of the original investigation can be found at http://dx.doi.org/10.1007/s004399900205

Y. Miura $\cdot$ S. Mardy · F. Endo · I. Matsuda $\cdot$ Y. Indo ()

Department of Pediatrics,

Kumamoto University School of Medicine,

Honjo 1-1-1, Kumamoto 860-8556, Japan

e-mail: yindo@kaiju.medic.kumamoto-u.ac.jp,

Tel.: +81-96-3735191, Fax: +81-96-3663471

Y. Awaya

Department of Pediatrics, Seibo International Catholic Hospital,

Tokyo, Japan

Y. Awaya $\cdot$ K. Nihei

Congenital Insensitivity to Pain with Anhidrosis Association,

Japan

K. Nihei

Department of Neurology, National Children's Hospital,

Tokyo, Japan 